\title{
Controlled Fracture Forming of Metal/Alpha-alumina Composite Wires
}

\author{
Kiyohiko Tatsuzawa, Tatsuhiko Aizawa and Junji Kihara \\ Department of Metallurgy, The University of Tokyo, 7-3-1 Hongo Bunkyo-ku, Tokyo 113.
}

Received February 2, 1995

\section{SYNOPSIS}

Controlled fracture forming(CFF) of metal/alpha-alumina composite wires and fibers was mainly studied with respect to the strength of alumina resintered into composite wires sheathed by nickel or austenitic stainless steel. The hardness of resintered alumina decreased with total reduction of cold working, because the densification of alumina should be prevented by contamination of sheath-metal constitutive elements during processing. In order to improve this resinterability, pure aluminum foil was inserted into the interface between metal sheath and presintered alumina, and worked by CFF processing. These green composite wires were resintered at $1623 \mathrm{~K}$ for $3.6 \mathrm{ks}$ in nitrogen atmosphere. This processing is effective to fabricate dense alpha-alumina/metal composite wires and fibers to be used in practical applications.

KEY WORDS

controlled fracture forming(CFF), metal/alpha-alumina, composite wire, swaging, rolling, resinterability.

\section{Introduction}

A continuous alpha-alumina fiber is one of the most attractive ceramics for fiber-reinforced metal matrix composites, because of sufficient high temperature strength and chemical stability. In the case of light metals ( $\mathrm{Al}, \mathrm{Mg}$ and its alloys), vacuum infiltration casting is available ${ }^{1-4)}$. However, in the case of refractory metal composites, this technique may be difficult to be used because of high casting temperature. On the other hand, the use of conventional powder metallurgy should lead to the breakage of alumina fiber, since alpha-alumina is brittle at room temperature. Hence, novel and nontraditional processing of metal/alpha-alumina composite fibers is strongly required.

Authors have been developing the controlled fracture forming (CFF) for ceramics ${ }^{5-10}$ ). In this process, the presintered ceramic billet is sheathed by the same alloys as matrix materials for a preform. During cold working by swaging and/or rolling, the controlled compressive stress is applied to the sheathed billet so that controlled fracture process should progress together with rear- rangement and flow of crushed alumina particles due to the plastic deformation of sheathed metal. Thus, green composite fiber of metal and ceramics can be easily produced by this process. This preform can be woven into a net work, since green composite fiber has sufficient strength and flexibility. Furthermore, through resintering of this woven preform, a complex shaped but rigid filtering unit member can be produced. In addition, when these preforms are assembled with the same metal powder as the sheathed metal, bulk composite material can be fabricated by hot pressing and/or HIP processing.

With respect to green wires and fibers, newly developed thin wiring process by CFF has succeeded in fabrication of metal/ceramic composite fibers with the diameter of about $200 \mu \mathrm{m}{ }^{9}$ ). Through mechanical testing of resintered fibers and EPMA analysis of their fractured surface, it was found that such constituent elements of sheath-metal as $\mathrm{Fe}, \mathrm{Cr}$ or $\mathrm{Ni}$ are uniformly distributed in alumina phase and they resulted in a nuisance to prohibit resintering and reduce the strength of final products ${ }^{10)}$. 
In the present paper, some fundamental studies are performed to aim to fabrication of preform wires and fibers for a filtering unit member. Both pure nickel and an austenitic stainless steel are employed as metal sheath. In order to improve the sinterability of crushed alumina, the aluminum foil is inserted into the interface between metal and alumina. This inserted materials should not prevent densification of alumina, because mixed aluminum in crushed alumina could react with residual air of compressed alumina or with nitrogen of sintering atmosphere, and may transform into oxide and/or nitride during resintering. On the basis of this consideration, the strength of alumina in resintered composite wires are mainly studied.

\section{Experimental procedure}

Commercial ultrafine-grained high purity alpha-alumina powder (TM-DAR, Taimei Chemical Co., Ltd.) with an average particle size of $0.1 \mu \mathrm{m}$ is employed for this study. Alumina powders were pressed into cylindrical compacts with a diameter of $5 \mathrm{~mm}$ and a length of about $23 \mathrm{~mm}$ at the pressure of $98 \mathrm{MPa}$. Compacts were sintered at $1443 \mathrm{~K} \sim 1593 \mathrm{~K}$ for $3.6 \mathrm{ks}$ in air. The presintered alumina compacts with relative densities of $66 \% \sim 90 \%$ were selected for the subsequent CFF process.

On the other hand, pure nickel and/or an austenitic stainless steel (type SUS-304 in JIS) were selected for metal sheath because of better corrosion resistance. As-received seamless pipes $(\mathrm{Ni} ; \phi 16.0 \times 1.2 t$, SUS-304; $\phi 10.5 \times 1.7 t)$ and $\operatorname{rod}(\phi 5)$ of metals were formed by cold swag-

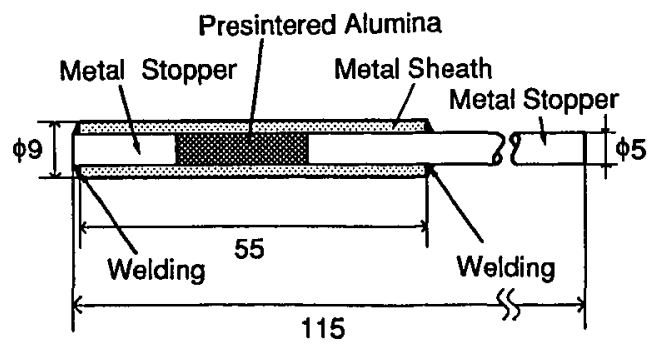

Fig. 1 Schematic representation of the presintered alumina sheathed by metal. ing to have the diameter nearly equal to that of presintered alumina. As shown in Fig.1, both the swaged pipe and the shorter stopping rod were welded in Argon. For the sake of stress relieving in swaged and welded materials, annealing for $3.6 \mathrm{ks}$ is applied in hydrogen atmosphere ( $\mathrm{Ni}$; at 923K, SUS-304; at $1173 \mathrm{~K}$ ). In order to produce the sample for conventional $\mathrm{CFF}$, only presintered alumina was located into the pipe, and finally the longer stopping rod was welded also in Argon. On the contrary, the presintered alumina wrapped by commercial pure Al-foil $(t=15 \mu \mathrm{m})$ were inserted into the pipe and welded in the same way.

Wiring of metal sheathed alumina by the $\mathrm{CFF}$ was performed in the following sequence. The prepared workpiece was cold swaged first to the diameter of $2.8 \mathrm{~mm}$, and this rod was further formed to the diameter of less than $0.86 \mathrm{~mm}$ by the wiring mill. In order to improve the crosssectional shape of alumina, the workpieces must be annealed at every $90 \%$ reduction $^{9)}$. To be noted, heat treatment must not be applied to the sample with Al-foil due to the risk of its melting.

These green composite wires were resintered at $1623 \mathrm{~K}$ for $3.6 \mathrm{ks}$ in a vacuum(for samples without Al-foil), and in nitrogen atmosphere(for samples with Al-foil).

In this study, to obtain the precise mechanical response of resintered alumina in composite wires, Vickers hardness testing with load of $4.9 \mathrm{~N}$ is employed for a polished cross-sectional surface of composite wires. The surface was also observed by the optical microscope and the electron probe microanalyzer (EPMA) for evaluation.

\section{Results and discussion}

\subsection{Forming limit of composite wires}

Through our recent study ${ }^{9}$ on the workability in the CFF process, we have found that the workpieces must be swaged as thin as possible and should be worked by the combined process of swaging and/or rolling and annealing at every $90 \%$ reduction. By this procedure, the composite fibers of stainless steel and alpha-alumina 
with the diameter of about $200 \mu \mathrm{m}$ were easily manufactured. In this case, intermediate annealing(IA) is indispensable to reduce work hardening in swaging and rolling. However, IA cannot be employed to the workpiece with Al-insert since inserted aluminum might be melted during the process. Due to this restriction, the forming limit must be reduced to the diameter of about $0.64 \mathrm{~mm}$ ( $99.4 \%$ reduction) in the case of the composite wires of stainless steel and alumina with Al-insert.

Looking back to this forming limit phenomenologically, the breakage of metal sheath is a main criterion to govern the forming limit of composite wires in CFF. The most important factor affecting this criterion is a cross-sectional area ratio $\left(A_{s h} / A_{c}\right) . \quad A_{s h}$ and $A_{c}$ denote the crosssectional areas of the sheathed metal and the ceramic, respectively ${ }^{5}$ ). In the case of stainless steel/alumina, we succeeded in thin wiring of the billets by this ratio of $2.7^{9}$. For fabrication of billets of nickel/alumina, we selected smaller value of 2.4 on the basis of some preliminary experiments. Forming limit of nickel/alumina composite wires is listed in Table 1. Maximum reduction in area $\left(R_{\max }\right)$ is calculated from $D_{\min }$ and $D_{o}$, where $D_{\min }$ is a minimum diameter of composite wire. $D_{o}$ is the diameter of sheathed metal, when inner diameter of sheathed pipe contacts directly with outer diameter $D_{c}$ of presintered alumina. Owing to an apporoximate formula by Yosida ${ }^{11)}$ for thickness of metal pipes during swaging, a current thickness $t_{0}$ can be written by

$$
t_{o}=\left[0.8\left(D_{i} / D_{o}-1\right)+1\right] t_{i}
$$

where $t_{i}$ is the initial thickness of the pipe, and $D_{o}$ and $D_{i}$ are the current and the initial outer diameter, respectively. From the above difinition of $D_{o}$,

$$
D_{o}=D_{c}+2 t_{o} .
$$

Then, substituting equa.(1) to (2), we have

$$
\begin{aligned}
& t_{o}=-\left(D_{c}-0.4 t_{i}\right) / 4 \\
& +\sqrt{\left(D_{c}-0.4 t_{i}\right)^{2}+8 t_{i}\left(0.2 D_{c}+0.8 D_{i}\right)} / 4
\end{aligned}
$$

\begin{tabular}{|c|c|c|c|c|c|}
\hline $\begin{array}{l}\text { Metal } \\
\text { Sheath }\end{array}$ & $\begin{array}{c}\mathrm{D}_{\mathrm{sh}} / \mathrm{D}_{\mathrm{c}} \\
(\mathrm{mm})\end{array}$ & $\begin{array}{c}\rho_{\mathrm{C}} \\
(\% \mathrm{TD}) \\
\end{array}$ & $\bar{A}_{\mathrm{sh}} / \mathrm{A}_{\mathrm{C}}$ & $\begin{array}{l}\mathrm{D}_{\min } \\
(\mathrm{mm})\end{array}$ & $\begin{array}{c}R_{\max } \\
(\%)\end{array}$ \\
\hline Swaged & $9.00 / 4.85$ & 70 & 2.34 & 0.86 & 99.1 \\
\hline Swaged & $9.00 / 4.84$ & 68 & 2.34 & $<0.86$ & $>99.1^{(*)}$ \\
\hline Swaged & $9.00 / 4.85$ & 72 & 2.44 & 1.52 & $97.1^{(* *)}$ \\
\hline Annealed & $8.90 / 4.86$ & 68 & 2.35 & 1.07 & 98.6 \\
\hline Annealed & $9.00 / 4.85$ & 67 & 2.36 & 1.74 & $96.2^{(*)}$ \\
\hline
\end{tabular}

Table 1 Forming limit of nickel/alumina composite wires. $(*)$ :annealed at $90 \%$ reduction, $(* *)$ :wrapped two turns in foil of aluminum.

Let us first discuss the effect of sheathed metal on the forming limit. With additional annealing of swaged sheath-metals before CFF, the forming limit of nickel/alumina billet was decreased from $99.1 \%$ to $98.6 \%$ in reduction. In the case of the sheath-nickel is a work-hardened material, the formability of nickel/alumina billet was improved by introducing intermediate annealing, since ductility of worked materials was recovered to the level for virgin materials. This IA-effect was the same manner as the case of stainless steel/alumina billet.

On the other hand, forming limit of nickel/alumina billet with Al-foil decreased from $99.1 \%$ to $97.1 \%$ in reduction. This is because aluminum with low strength and high ductility may deteriorate flowability of crushed alumina particles during working. In order to obtain more thinner wires and/or fibers, metals and alloys with high strength than nickel should be selected for the sheath. At present, thin wiring of stainless steel/alumina with Al-foil is still on research.

\subsection{Hardness of resintered alumina.}

As indicated in our previous study ${ }^{10}$, the constituent elements of sheath-metal are forced to be scaled off and mixed with the crushed alumina. Owing to active movement and rearrangement of crushed alumina particles, these mixed metal fragments are thought to be crushed into smaller fractions and further distributed in the whole assembly of alumina particles. Since densification of alumina is prevented by this inclusions of sheath-metal elements in CFF process, the tensile strength of resintered composite fibers must be much lowered than that expected. Hence, let us reconsider this contamination effect through 


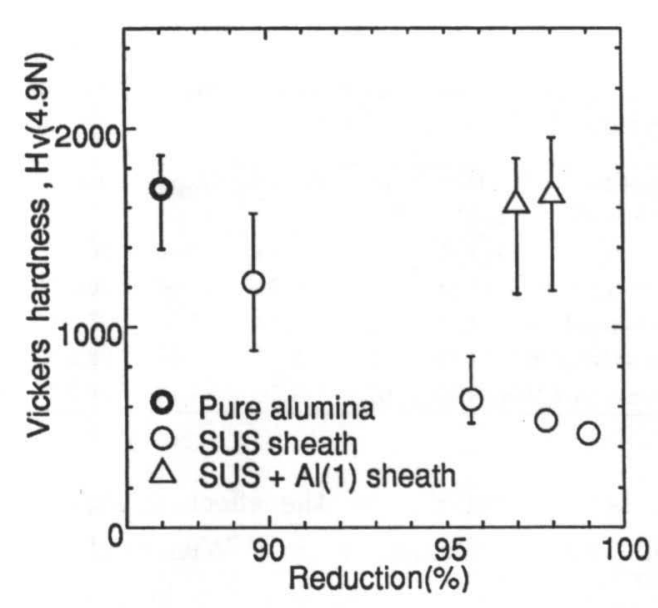

Fig. 2 Vickers hardness of resintered alumina in composite wires sheathed by stainless steel (SUS sheath) as a function of reduction in area. $\mathrm{SUS}+\mathrm{Al}(1)$ sheath: inserted one sheet of aluminum foil $(13 \mathrm{mg})$ into the interface.

Vickers hardness testing of the resintered alumina in composite wires with and without Al-insert.

Fig.2 shows change of Vickers hardness of resintered alumina in composite wires sheathed by stainless steel with the reduction in area. Two types of samples are directly compared with the reference to the Vickers hardness of pure alumina resintered from compacted original powders at $1623 \mathrm{~K}$ for $3.6 \mathrm{ks}$ in vacuum. Samples without Alfoil were resintered at $1623 \mathrm{~K}$ for $3.6 \mathrm{ks}$ in vacuum. While, those with $\mathrm{Al}$-foil were resintered at $1623 \mathrm{~K}$ for $3.6 \mathrm{ks}$ in nitrogen atmosphere.

The measured value of hardness 1700 for pure alumina seems to be lower than those reported in literature $(2000 \sim 3000)^{12)}$. This is because the present reference materials still have pores left inside and the standard alumina is completely pore-free. Clearly seen in Fig.2, at the absence of Al-foil, hardness value decreases monotonically with reduction. On the contrary, at the presence of Al-foil, no decrease of hardness is seen in Fig.2, and, even in the higher reduction of area, hardness is kept nearly equal to the original value for pure alumina.

Let us further investigate the role of $\mathrm{Al}$-insert foil to prevent the contamination of constituent elements from the sheath-metal. Photo.1 shows

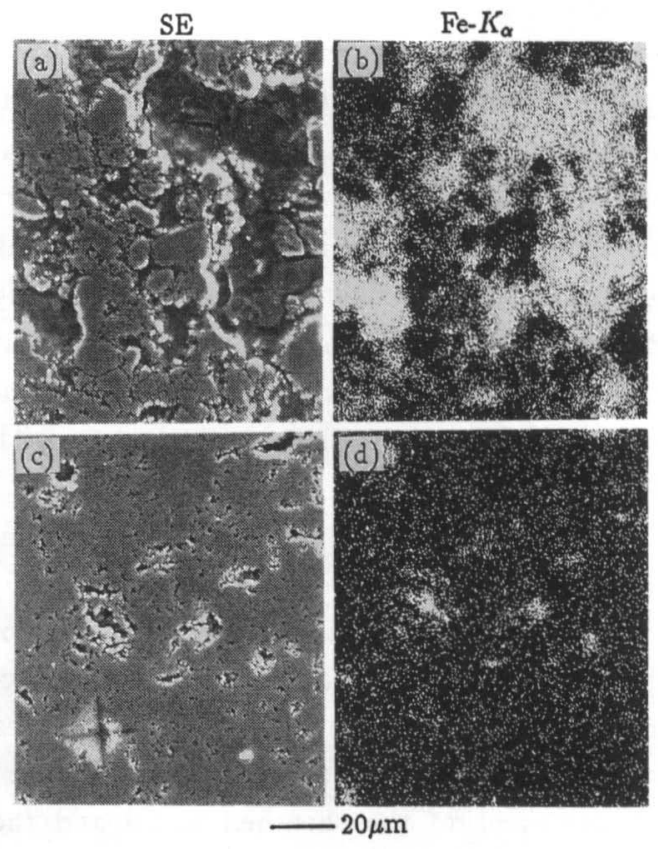

Photo.1 SE and Fe- $K_{\alpha}$ images by EPMA for resintered alumina of composite wires sheathed by stainless steel. (a),(b): sheathed by only stainless steel with $95.7 \%$ reduction and (c),(d): specimen of inserted aluminum(13mg) with $97.0 \%$ reduction. Wires were resintered at $1623 \mathrm{~K}$ for $3.6 \mathrm{ks}$.

constituent element distributions by EPMA for resintered alumina with and without Al-insert. In spite of the center portion of alumina, iron contamination from sheath-metal can be detected from a sample without Al-insert(Photo.1(b)). This reveals that fragments should be scaled off from sheath-metal and be mixed into the crushed alumina particles during cold working. In contrast to the above contamination, when only oneturn wrapping of sintered alumina by a sheet of Al-foil with the thickness of $15 \mu \mathrm{m}$ inhibits fragments from stainless steel to mix with the crushed alumina during cold working as shown in Photo.1(d). Owing to in-situ reaction of Al-insert with nitrogen and residual air, dense resintering is thought to take place for the crushed and refined alumina particles. Any aluminum nitrides cannot be detected by EPMA. This is because the peaks for aluminum and nitrogen are difficult or nearly impossible to be distinguished.

Let us discuss on the change of hardness for 


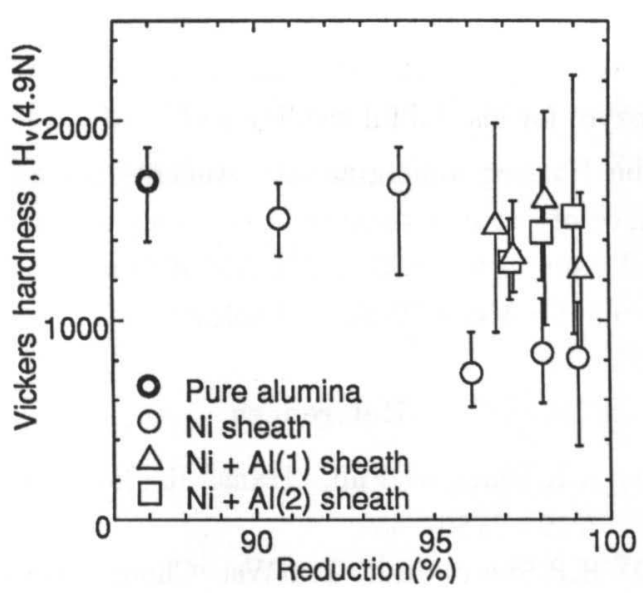

Fig. 3 Vickers hardness of resintered alumina in composite wires sheathed by nickel as a function of reduction in area. $\mathrm{Ni}+\mathrm{Al}(1)$ sheath: inserted one sheet of aluminum foil(14mg) into the interface, $\mathrm{Ni}+\mathrm{Al}(2)$ sheath: two sheets of aluminum foil $(26 \mathrm{mg})$.

the resintered alumina in the composite wires sheathed by pure nickel.

As shown in Fig.3, just predicted by the previous results, hardness of resintered alumina decreases monotonically with reduction of area for samples without Al-insert. While, it is indifferent to reduction of area by a constant value of hardness nearly equal to the original reference data for samples with $\mathrm{Al}$-insert. As shown in Photo.2, contamination of nickel from a sheath-metal is prevented by a one-turn Al-insert.

Two main concerns to be interested here are: 1) Controlled fracture process for flow and rearragement of crushed alumina particle is always accompanied with mechanical mixing and homogenization process of crushed particles scaled off from a sheath irrespectively of the employed materials as a sheath-metal. Hence, homogeneous mixing of constituent elements from a sheath results in contamination to alumina particles and deterioration of resinterability. Mixing of prefered elements as aluminum leads to improvement of resinterability with aid of its active oxidation and/or nitriding, and, 2)Owing to the quality control in mixing process of constituent elements from sheath-metal, original mechanical properties for the initial presintered billet are not deteri-

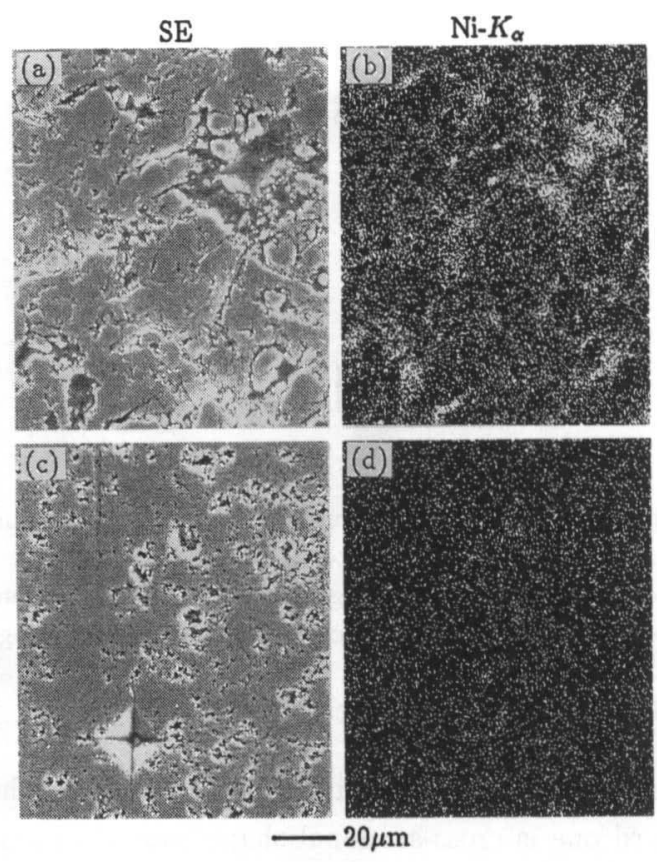

Photo.2 SE and Ni- $K_{\alpha}$ images by EPMA for resintered alumina of composite wires sheathed by nickel. (a),(b): sheathed by only nickel with $96.1 \%$ reduction and (c),(d): specimen of inserted aluminum(14mg) with $96.8 \%$ reduction. Wires were resintered at $1623 \mathrm{~K}$ for $3.6 \mathrm{ks}$.

orated during thin wiring. Then without contamination, resinterability must be improved by refinement of crushed alumina particles together with this thin wiring.

\subsection{Some remarks in a future work}

By this processing, we can fabricate easily metal composite wires with the core of dense alumina. For further research and development, three problems must be investigated.

At the first, as shown in Photo.3, these composite wires with dense alumina have residual cavities along the interface between alumina and sheath-metal. These cavities could be originated by densification of crushed alumina particles during resintering: improvement of resinterability brings to larger shrinkage. The cavity around the interface should weaken the strength of the composite wire; the cavity must be eliminated by the resintering technique through HIP and hot pressing. Secondary problem is further reduction of wires with $\mathrm{Al}$-insert into thin composite wires 

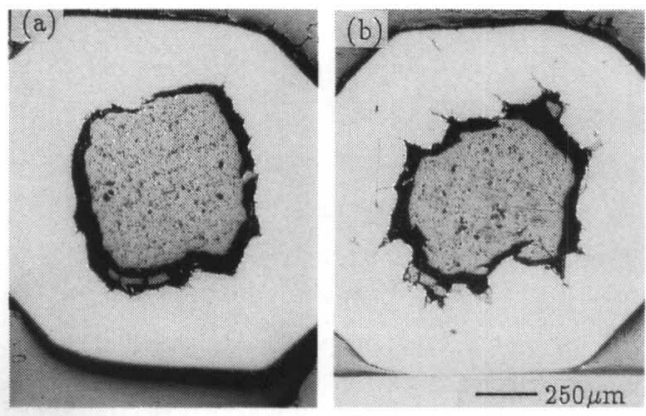

Photo.3 Optical microstructures of resintered composite wires. (a): after sheathed by stainless steel with aluminum(13mg) worked $97.0 \%$ reduction, (b): after sheathed by nickel with aluminum(14mg) worked $97.2 \%$ reduction. Wires were resintered at $1623 \mathrm{~K}$ for $3.6 \mathrm{ks}$ in nitrogen atmosphere.

beyond the forming limit of $97 \%$ reduction. The third one is cross-sectional shape control of alumina in resintered composite wires. As shown in Photo.3, the shape of composites inserted aluminum has an irregular shape. This is because work hardening during cold working decreases the ductility of metal sheath. Further studies are taking place to overcome the above mentioned difficulties and to extend the present compositewiring to practical forming.

\section{Conclusions}

Controlled fracture forming(CFF) of alphaalumina/metal composite wires and fibers was mainly studied with respect to the strength of alumina in the resintered composite wires. In order to improve resinterability of alumina, pure aluminum foil was inserted into the interface between metal sheath and presintered alumina, and worked by $\mathrm{CFF}$ processing. These green composite wires were resintered at $1623 \mathrm{~K}$ for $3.6 \mathrm{ks}$ in nitrogen atmosphere. This processing is effective to fabricate dense alpha-alumina/metal composite wires and fibers with sufficiently higher strength than the composite wires without Al-foil insert.

\section{Acknowledgments}

Authors would like to express great thanks to Mr. Seiji Ohtake (RCAST, The University of Tokyo) for his skillful welding and to Mr. Toshio Abe (former undergraduate student) for assistance of our experiments. This work was financially supported by Grant-in-Aid of Amada Foundation for Metal Work Technology.

\section{References}

1) A.K.Dhingra: Phil. Trans. R. Soc. Lond., A294(1980), 559.

2) H.R.Shetty and Tsu-Wei Chou: Metall. Trans. A, 16A(1985), 853.

3) J.T.Evans: Acta Metall. 34(1986), 2075.

4) J.A.Isaacs and A.Mortensen: Metall. Trans. A, 23A(1992), 1207.

5) T.Aizawa, X.M.Chen and J.Kihara: Proc. 1st Japan International SAMPE Symposium, (1989), 781.

6) X.M.Chen, J.Kihara and T.Aizawa: Advanced Technology of Plasticity, 2(1990), 1027.

7) T.Aizawa, X.M.Chen and J.Kihara: Proc. 2nd Japan International SAMPE Symposium, (1991), 179.

8) X.M.Chen, T.Aizawa and J.Kihara: Mater. Sci. Eng., A151(1992), 45.

9) K.Tatsuzawa, T.Aizawa and J.Kihara: Advanced Technology of Plasticity 1993, Ed. by Z.R.Wang and $\mathrm{Hu}$ Yuxin, Inter. Academic Pub., Beijing, vol.1(1993), 116.

10) K.Tatsuzawa, T.Aizawa and J.Kihara: Proc. 1993 Powder Metall. World Congress, Ed. by Y.Bando and K.Kosuge, Japan Soc. Powder and Powder Metall., (1993), 622.

11) K.Yoshida: Press Working(in Japanese), 21(1983), 33.

12) J.R.Hague, J.F.Lynch, A.Rudnick, F.C.Holden, and W.H.Duckworth Eds.: Refractory Ceramics for Aerospace (A Materials Selection Handbook), Amer. Ceramic Soc., Columbus, (1964), 207. 